\title{
sciforum
}

Conference Proceedings Paper

\section{Drought: An external Agri-project Risk Analysis for Thabana Morena Constituency Number 52, Mafeteng, Lesotho}

\author{
Bernard Moeketsi Hlalele * \\ Department of Business Support Studies, Faculty of Management Sciences, Central University of Technology, \\ Free State, Bloemfontein, 9300, South Africa \\ * Correspondence: hlalele.moeketsi@gmail.com
}

\begin{abstract}
Climate change has proven to increase the odds of worsening drought events around the globe, resulting in adverse effects on society, economy and environment. The current study aimed at characterising drought events in the study area in order to alert responsible government department and all other relevant authorities for proactive response before it is too late. The researcher collected precipitation datasets from NASA data portal alongside the main Thabana Morena road. For quality control, both homogeneity and stationarity test were conducted. Prior to this, outliers were detected and replace back by Expectation Maximum algorithm aided by SPSS. Three computer programmes were used in this study, namely; DMAP, XLSTAT and PAST3. Drought was quantified on two temporal time scales to pick up both agricultural and hydrological drought episodes. Major results indicated most stations having homogenous precipitation datasets and as such only two distant stations (Ha Thakanyane and Ramarothole) were used in further analysis. Ha Thakanyane and Ramarothole depicted constant and statistically increasing severe drought conditions on both temporal scales over 38 years respectively. The situation warrants sustainable off-agricultural interventional measures by the government and all relevant stakeholders to protect environment and human lives that are dependent on rainfed agriculture for livelihood.
\end{abstract}

Keywords: drought; hazard; risk; Thabana Morena; SPI; Agri-project risk

\section{Introduction}

A period in time whereby conditions are drier than usual and there is a lesser amount of rainfall than normal for a long period of time; for several weeks, months and even years which lead to waterrelated problems is defined as drought (Praveen, Ramachandran, Jaganathan, Krishnaveni, \& Palanivelu, 2016). Nevertheless, there is no specific definition of drought; but it can be classified into four essential types. In this study, drought is described as a severe state which is has undesirable dry spell which has negative impacts on the economy, society and environment. The four essential types of drought are: meteorological drought, hydrological drought, agricultural drought and socio-economic drought. (i) Meteorological drought is simply the degree of dryness compared to normal conditions and this is irregular over time and certain regions (Olivares Campos, 2016), (ii) hydrological drought on the other hand is deficient rainfall which results into grave reduction in run-off streamflow, inflow into storage reservoirs and revitalizing of groundwater (Orlando Olivares \& Zingaretti, 2018), (iii) Agricultural drought refers is a deficit of soil moisture to sustain plants and livestock in that way causing weakened growth and reduced produce (Tefera, Ayoade, \& Bello, 2019) and Socio-economic drought is a period in time whereby human activities are negatively affected by reduction in water availability and precipitation. (Praveen et al., 2016). As much as all these types of drought have a linkage, one leads to another and every now and then overlaps; thus, agricultural drought is regarded 
as of prime importance and a roadmap in this study. The figure 1 below illustrates the interrelationship of the types of drought.

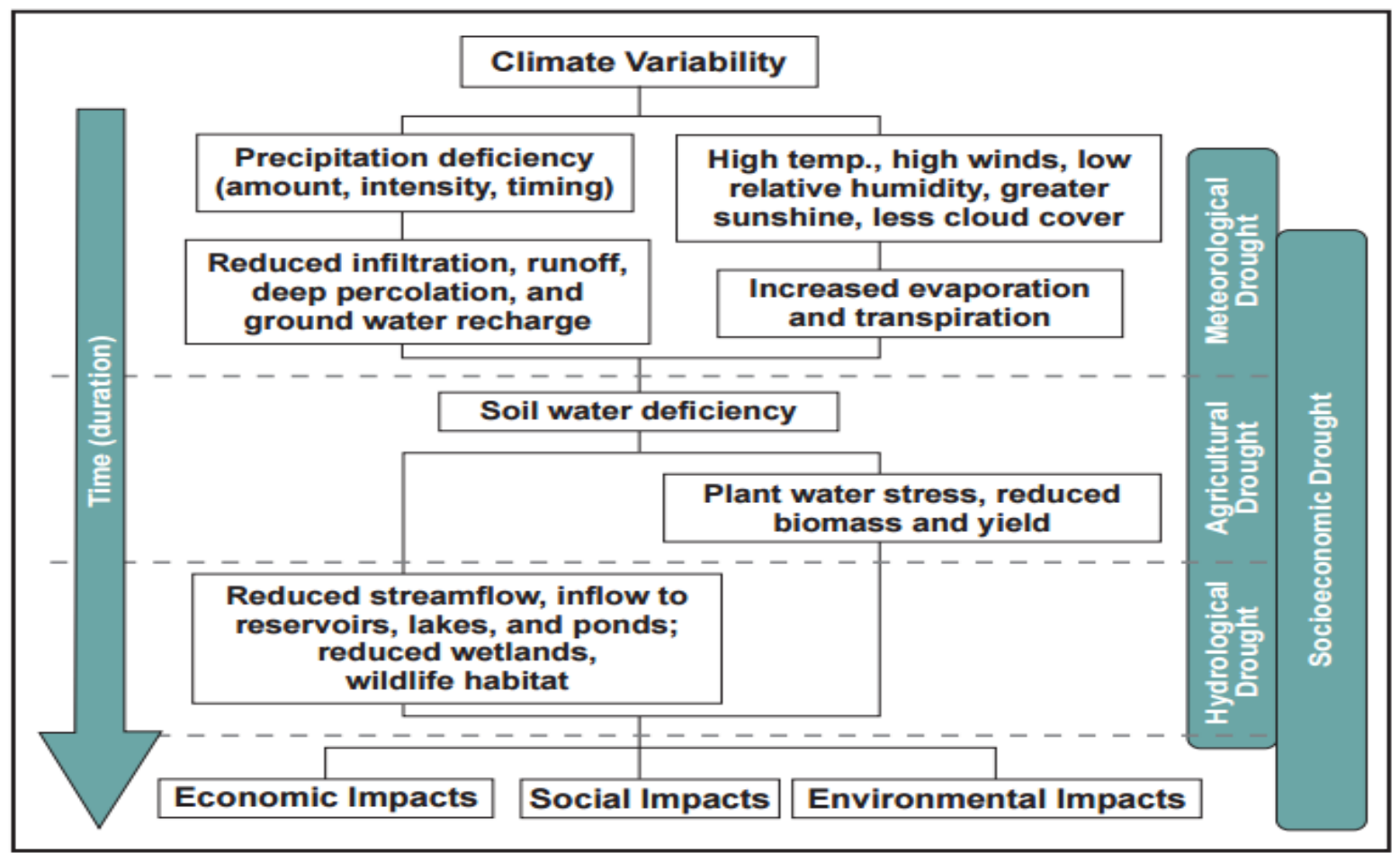

Figure 1. Sequence of drought types' occurrence and their impacts.

Source: National Drought Mitigation Centre, 2012.

\section{Key Driving Forces behind Drought Events}

\section{El Niño-Southern Oscillations}

Despite the fact that numerous continents around the world pass through the separation between two hemispheres, Africa is the only continent that lies within them all and is affected by numerous climatic conditions. (Roman-Cuesta, 2007). As a result, this continent receives conventional rainfall. (Choi, An Prof., Yeh, \& Yu, 2013). This also escalates to different climatic conditions such as El Nino. El Nino is a recurring climate pattern which is caused by changes in temperatures of water by warming the eastern Pacific, and therefore affecting the global climate. (Ali \& Ali, 2011). This natural occurrence is responsible for exacerbating drought events in the southern hemisphere. (Ali \& Ali, 2011). In accordance to Keil, Zeller, Wida, Sanim, \& Birner (2008), drought is a resultant of the shifting, changing weather patterns. On the other hand, it is also a belief that droughts chiefly transpire because of natural occurrences due to the earth and atmospheric systems. In contrast, Granzow-de la Cerda, Lloret, Ruiz \& Vandermeer (2012) are of the belief that no one knows for sure why droughts occur, but many scientists believe that there is an affiliation between drought occurrence and El Nino events. Thorough comprehension of the relationships between droughts and repeated changes in high and low pressures from one side of the Pacific to the other linked with La Nina allow scientists to formulate improved predictions of this calamitous drought hazard. (Ryu, Svoboda, Lenters, Tadesse, Knutson 2010). Both El Nino and La Nina form the El Nino-Southern Oscillation (ENSO) cycle. ENSO is a recurring climate pattern whereby temperature fluctuate between the ocean and atmosphere in the east-central Equatorial Pacific, approximately between the International Date Line and 120 degrees West (Olivares Campos, 2016). Nevertheless, these two events happen every 2-7 years with El Nino events occurring 
more often than those of La Nina (Tefera et al., 2019). There has been a rising trend in global weather disasters since 1980, and with extreme climatic events such as droughts. (Orlando Olivares \& Zingaretti, 2018). Comprehending phenomena such as ENSO is pivotal because of the possibility that it could cause an enormous loss of property, destruction to the environment and the loss of human life. Conjectures by ENSO, tracing and monitoring is of a significant role to insurers, government authorities and other pertinent stakeholders for drought management for proactive planning against unfavourable impacts such as acute climatic changes like drought events. (Praveen et al., 2016)

\section{Solar activity (Sunspots number)}

Sunspots could also be another source associated with drought. Sunspots commonly last for a period of approximately 11 years. (Minckley, Roulston, \& Williams, 2013). They are described as cool surface areas on the sun that are visible in pairs and are darker in comparison with other parts of the sun. These spots have a strong magnetic field and rotate like a giant hurricane. (Mèthy, Damesin, \& Rambal, 1996). These authors also affirm that several authors have acknowledged that sunspots have impacts on temperature, precipitation, length of growing seasons, air circulation, atmospheric pressure, high altitude, wind speed and other natural phenomena around the world. Furthermore, Xiao \& Zhuang (2007) construct solar activity as a main cause of cyclic deviations of the global climate through triggering of the evaporation processes. Scientists have also shown that sunspot numbers and drought events are correlated. For instance, during solar activity- drought events take place at solar maximum (Solheim, Stordahl, \& Humlum, 2011). This occurrence is related to climatic conditions where temperatures become high during solar maximum (Minnis, 1958). Solar energy is the principal energy source as well as control on evaporation; therefore, distributions of insulation and evaporation are strongly linked. (Siingh et al., 2011). The energy from the sun is the central source of energy present for heating the surface of the planet earth. This energy supplied by the sun is an outcome of its activity and it differs with time. The major cycle of the sun is eleven years. The major cause of drought events is believed to be the solar activity (Ghormar, 2014). The coefficient of correlation between insulation and evaporation ranges between 0.820 and 0.948 and values of the calculated solar radiation are used in the computation of the Potential Evapotranspiration (PET) in Penman equation (Abarca del Rio, Gambis, Salstein, Nelson, \& Dai, 2003). The solar radiation that falls on the earth's surface depends on the distance it travels to the object and the angle at which rays hit an area or object. (Méthy et al., 1996). The universal law for the intensity of radiation, distinctively the sine law of sunlight states that the sunlight always strikes the high latitude obliquely, so it spreads out more and is less intense. (Minckley et al., 2013).

\section{Drought Impacts}

There are several impacts of drought and these include: mass starvation, famine and a pause or sometimes an end to economic activity particularly in areas where rain fed agriculture is the main stay of the rural economy $(4$, n.d.). It is generally known that drought is the chief cause of forced human migration and environmental refugees, deadly conflicts over the use of diminishing natural resources, food insecurity and starvation, a damage to significant habitations and as well as loss of biological diversity; volatility of socio-economic conditions, poverty and unpredictable climatic conditions through reduced carbon sequestration possibility (Roman-Cuesta, 2007). Drought and desertification impacts are among the pricey incidents or occurrences in Africa, for instance, the prevalent destitution as well as the unstable economy of many African countries which in actuality depend on climatesensitive segments such as rain-fed agriculture. All plants and animal life present in a particular region which are not resilient to drought are most likely to go into extinction. (Nagamuthu \& Rajendram, 2015). The collective results of drought and bush burning (during dry seasons) have made the plants to go extinct and animals to drift into safer places. Drought, land degradation and desertification have had grave impacts on the richness and variety of fauna and flora (Francisco, 2013). Moreover, plants biodiversity will alter with time, unpleasant species will dominate, and total biomass production will 
dwindle (Khan \& Gomes, 2019). Plants and animals are reliant on water, like people. Drought can minimize their food supplies and damage their habitats. Occasionally, this damage lasts for only a limited period of time, and other times it is irrevocable. Drought can also affect people's health and safety. For example, drought impacts on society include anxiety or depression about economic losses, conflicts due to water shortages, reduction of income, fewer recreational activities, and increase of heat stroke incidents and sometimes loss of human lives. Moreover, drought conditions can also grant a considerable increase in wildfire risk. This is due to withering of plants and trees from lack of precipitation, scourge insect infestations, and diseases, all of which are associated with drought. (Prokurat, 2015). Lengthy periods of drought can cause more wildfires and more powerful wildfires, which impinge on the economy, the environment as well as the society in a number of ways like destroying neighbourhoods, crops and habitats (Do Amaral, Cunha, Marchezini, Lindoso, Saito, \& Dos Santos Alvala, 2019). Again, drought not only always offers similar instant and remarkable visuals related with occurrences such as hurricanes and tornadoes, but it still has a huge price tag. In point of fact, droughts are the second in rank types of phenomena that are associated with billion-dollar weather disasters for the past three decades (Nagamuthu \& Rajendram, 2015). With staggering yearly losses close to $\$ 9$ billion annually, drought is a severe hazard with socioeconomic risks for most African countries. (Siingh et al., 2011). These pricey drought impacts come in different forms. For instance, the economic impacts of drought include farmers who lose money because drought destroyed their crops or worse ranchers who may have to spend more money for animal feeds and irrigation of their crops. Economic impacts can either be direct or indirect. Directly, it could be a decrease in dairy production and indirectly, it could be observed through increases in the price of the cheese (Francisco, 2013).

\section{Materials and Methods}

The monthly rainfall dataset of this study was obtained from National Aeronautics and Space Administration (NASA) data portal. This dataset was used as the only input parameter for Standardized Precipitation Index computation. Standardized Precipitation Index (SPI) is plainly described as a normalised index that signifies a likelihood of a rainfall occurrence of an observed rainfall amount in comparison with the rainfall climatology at a particular geographical location over a long-term reference period (Siingh et al., 2011). Furthermore, Yusof, Hui-Mean, Suhaila, Yusop, \& Ching-Yee (2014) affirm that SPI is a probability index that offers an enhanced demonstration of both abnormal wetness and dryness than any Palmer indices such as Palmer Drought Severity Index (PDSI). The value of this index is that it can be computed for different time scales, for that reason, issuing early warming of drought and its severity (Gaas, 2018). This index is appropriate for risk management purposes (Verma, Verma, Yadu, \& Murmu, (2016). Moreover, this index is advantageous in that precipitation is the only parameter in its computation therefore making it less complex. Conversely, the weakness of this index is that it can only compute the precipitation deficit; values founded on initial data may alter, and values vary as the period of record grows (Jordan, 2017). The table 1 below illustrates the values of SPI categorisation.

Table 1. SPI categorisation.

\begin{tabular}{ccc}
\hline SPI Value & Category & Probability $\%$ \\
\hline$\geq 2.0$ & Extremely wet & 2.3 \\
\hline 1.5 to 1.99 & Very wet & 4.4 \\
\hline 1 to 1.49 & Moderately wet & 9.2 \\
\hline-0.99 to 0.99 & Near normal & 34.1 \\
\hline-1.0 to -1.49 & Moderately dry & 9.2 \\
\hline-1.5 to -1.99 & Severely dry & 4.4 \\
\hline$\leq-2.0$ & Extremely dry & 2.3 \\
\hline
\end{tabular}

Source : Hlalele, 2016. 
The SPI calculations are founded on the fact that precipitation increases over a fixed time scale of interest, for instance ; SPI-3, SPI-6, SPI-9, SPI-12, SPI-24 and SPI-48, so from that a series is integrated in gamma probability distribution which is apt for this climatological precipitation time series. (Yusof et al., 2014). The gamma distribution is described by the following density function.

$$
g(x)=\frac{1}{\beta^{\alpha} \Gamma(\alpha)} x^{\alpha-1} e^{-x / \beta} \quad \text { for } \mathrm{x}>0
$$

Where $\alpha$ and $\beta$ are estimated for each station as well as for each month of the year.

$$
\begin{aligned}
& \alpha=\frac{1}{4 A}\left(1+\sqrt{1+\frac{4 A}{3}}\right) \\
& \beta=\frac{\bar{x}}{\alpha}
\end{aligned}
$$

where $\mathrm{A}=\ln (\bar{x})-\frac{\sum \ln (x)}{n}$, and $\mathrm{n}=$ number of observations

After these parameters have been estimated then their resulting values are used to calculate cumulative probability as;

$G(x)=\int_{0}^{x} g(x) d x=\frac{1}{\beta^{\alpha} \Gamma(\alpha)} \int_{0}^{x} x^{\alpha-1} e^{-x / \beta} d x$

In cases where $t=x / \beta$ then an incomplete gamma function becomes

$$
G(x)=\frac{1}{\Gamma(\alpha)} \int_{0}^{x} t^{\alpha-1} e^{-t} d t
$$

Since gamma function is undefined at $\mathrm{x}=0$ then the cumulative probability is calculated from the following equation (Rahmat, Jayasuriya, \& Bhuiyan, 2012):

$H(x)=q+(1-q) G(x)$,

where $q$ is the probability of a zero and $G(x)$ the cumulative probability of the incomplete gamma function. If $m$ is the number of zeros in a precipitation time series, then $q$ can be estimated by $m / n$. The cumulative probability is then transformed to the standard normal random variable $z$ with mean zero and variance one, which is the value of the SPI (Yusof et al., 2014). In the event where it is standardized, the potency of the irregularity is categorised as illustrated in Table $\mathrm{xx}$, where the table also demonstrates the corresponding probabilities.

\section{Data Quality Control}

Homogeneity tests are carried out to scrutinize statistical properties of a certain dataset in statistics. In essence, the tests thoroughly look at the location. stability and variations which are local within the time series over time (Abraham \& Yatawara, 1998). The author also confirms that this occurrence is the same as testing statistical distribution, for that reason identifying if there are any changes in the distribution. The test is also carried out to evade false or unauthentic results from the data sets. (Hosseinzadeh Talaee, Kouchakzadeh, \& Shifter Some'e, 2014). A non-parametric Pettitt's test was used. Outliers and missing were identified and substituted by Expectation Maximum algorithm (EIM) with the help of SPSS software. EM is described as a statistical algorithm appropriate to be used when there are missing or hidden values in the data sets (Lobato \& Velasco, 2004). Tan \& Ylmaz (2002) construct that EM is a well-liked too used in statistical estimation problems that involve data which is 
incomplete. Likewise, Technology \& Bay (2001) define EM as an algorithm that allows parameter estimation in probabilistic models with data which is not complete.

Before carrying out any data analysis, it is essential to assess the apparent proof of patterns and trends in the climate data (Kliewer \& Mertins, 1997). Non-parametric Mann-Kendall test is used in the study to assess if any trends existed. This test is universally used to identify monotic trends in series of environmental, climate and hydrological dataset. The null hypothesis $\left(\mathrm{H}_{0}\right)$ means that data came from a population with autonomous realisations is identically distributed. The alternative hypothesis $\left(\mathrm{H}_{\mathrm{a}}\right)$, means that data follows a monotonic trend. The Mann-Kendall statistic indicates how strong and weak two variables are associated and show correlation direction (Kliewer \& Mertins, 1997). One of the advantages of this statistic is that, the data does not necessarily have to follow any definite probability distribution. The test was conducted simultaneously with a non-parametric Pettitt's test to gauge data homogeneity and descriptive statistics.

\section{Parameters Used to Characterise Drought}

The temporal characteristics are those features of a hazard associated with time and they are commonly linked with questions such as the following: When does the hazard occur? What is the frequency of the occurrence? What is the duration of the hazard? How fast do they hit and how conventional are they? (Andreadis, 2005: Van Niekerk, 2011). Drought intensity is described in numerous ways by different academics; nevertheless, in accordance to Pope et al (2013) intensity is a degree of insufficient rainfall. The authors further explain that, intensity can be defined as a result of duration as well as intensity. Abdulmaleket al. (2013) affirms that drought intensity gauges how far rainfall is below the average precipitation of the region. Understanding intensity can be used as a way of ascertaining the feasible impact of a hazard on communities. Understanding intensity can be used as a way of ascertaining the feasible impact of a hazard on communities as well as the levels of risk at which elements are exposed to (Van Niekerk, 2011). This aspect of drought is conveyed in several parameters such as the Standard Total Accumulative Dry Spell (STCD), Average Dry Spell Index (ADSI), Longest Multi year Drought (LMYD) and Largest Single Year Drought (LSYD) (Abdulmaleket et al., 2013). STCD signify the total cumulative drought index used. One more parameter used to quantify the same aspect is ADSI. LMYD and LSYD are other parameters obtained from drought indices such as SPI whose high values have negative outcomes on every facet of the environment, including socio-economic situation of communities. ADSI values offer valuable knowledge on the region's characteristics essential for arrangement of water resources as well as irrigation projects. Areas with low values need special attention. Likewise, The ADSI values are of great significance to decision makers for the planning of agricultural projects of the affected areas for future. The LSYD also is significant to take into consideration in crop cultivation given that crops barely survive its high values. So, these four parameters are defined by the equations below:

$$
\mathrm{ADSI}=\mathrm{STCD} / \mathrm{N}
$$

where $\mathrm{N}=$ total number of years of the series

$$
\text { LMYD = Maximum of any successive years }
$$

LSYD = Maximum drought index value of the single year

\section{Drought Frequency and duration analysis}

For a long-term planning to be effective in water projects such as irrigation and dam sizing purposes, there has to be an analysis of both dry and wet spells from a climatic and hydrometeorological standpoint. (Abdulmaleket al., 2013). In drought analysis a period declared as dry when $\mathrm{SPI}<0$. These are some of the parameters used to calculate the drought duration: Longest Dry Spell Duration (LDSD), Drought Tendency (DT) and Average Dry Spell Duration (ADSD). LDSD is described as the highest of any consecutive dry spells that occurred on one occasion through the study record $\mathrm{N}$. 
High values of both LDSD and ADSD it means that water resources planning must be considered in that particular region. Nevertheless, DT is the ratio which involves the total number of dry spell cases to the wet spell cases. This parameter measures the predisposition of the study area which suffers from the dry spells, thus it measures the frequency of a hazard under consideration. These are defined by the following equations:

$$
\operatorname{LDSD}=\sum_{i}^{N} D i, \mathrm{i}=1,2 \ldots \mathrm{N}
$$

$$
\mathrm{DT}=\sum D / \sum W
$$

$$
\mathrm{ADSD}=\sum D / N
$$

If successive dry spell cases (D) are followed by a wet spell, like $\mathrm{D}, \mathrm{D}, \mathrm{D}, \mathrm{W}, \mathrm{D}$ then $=\sum D=4$, and $\mathrm{N}=2$ since an interrupted sequence of several cases of (D) constitute only one dry spell event.

A frequency analysis offers an early warning system. Disaster managers and appropriate stakeholders have the ability to foresee when the next incident will take place. (Sobrino et al. 2011). Hydro-climatic hazards such as drought have a propensity of following a seasonal pattern. When the number of times and the length of a hazard such as drought are known, such knowledge helps in planning accordingly (Hlalele, 2016). In a frequency analysis, approximation of the probability of an incidence of future occurrences is established on a primary base for risk management. (Yuliang et al. 2014). Again, it is used to foresee how frequently a hazard event happens over space and time (Des Jardins, 2012).

\section{Results and Discussion}

Table 2. Stations used alongside Thabana Morena Road.

\begin{tabular}{cccc}
\hline Station & Elevation $(\mathbf{m})$ & Latitude & Longitude \\
\hline Ha Thakanyane & 1657.31 & -30.021 & 27.454 \\
\hline Mount Tabor Mission & 1665.34 & -29.998 & 27.433 \\
\hline Ha Ngoae & 1665.34 & -29.985 & 27.424 \\
\hline Ha Lekoatsa & 1665.34 & -29.939 & 27.423 \\
\hline Mount Olivet & 1665.34 & -29.837 & 27.353 \\
\hline Ha Ramarothole & 1665.34 & -29.773 & 27.282 \\
\hline Ha Mafeteng CBD & 1665.34 & -29.823 & 27.247 \\
\hline
\end{tabular}

Table 2 shows the selected stations with their respective geographic coordinates from precipitation data was collected. These stations were strategically selected alongside the main Thabana Morena road from Ha Thakanyane to Mafeteng CBD (at Ha Leuta). These stations were selected in such a way to capture the entire Thabana Morena for drought analysis which seem to have damaged the area. Most of the selected stations seem to share a common elevation. 


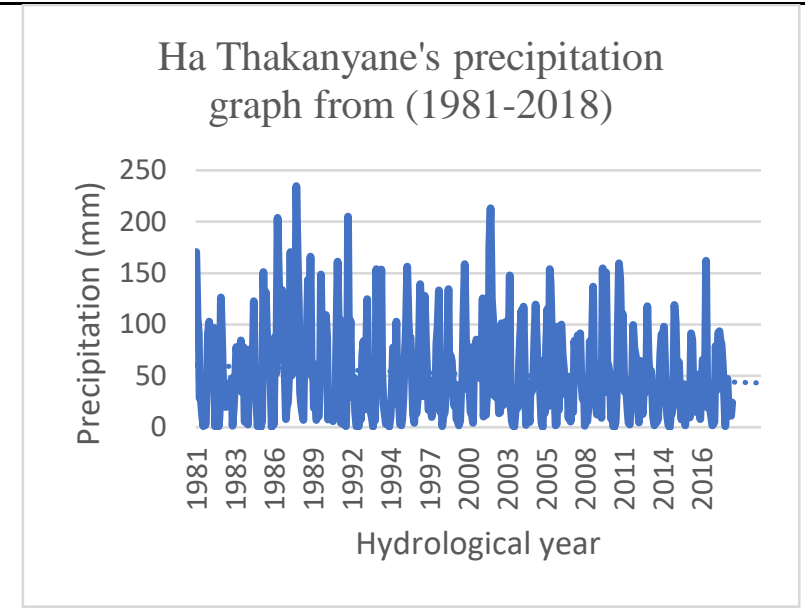

a

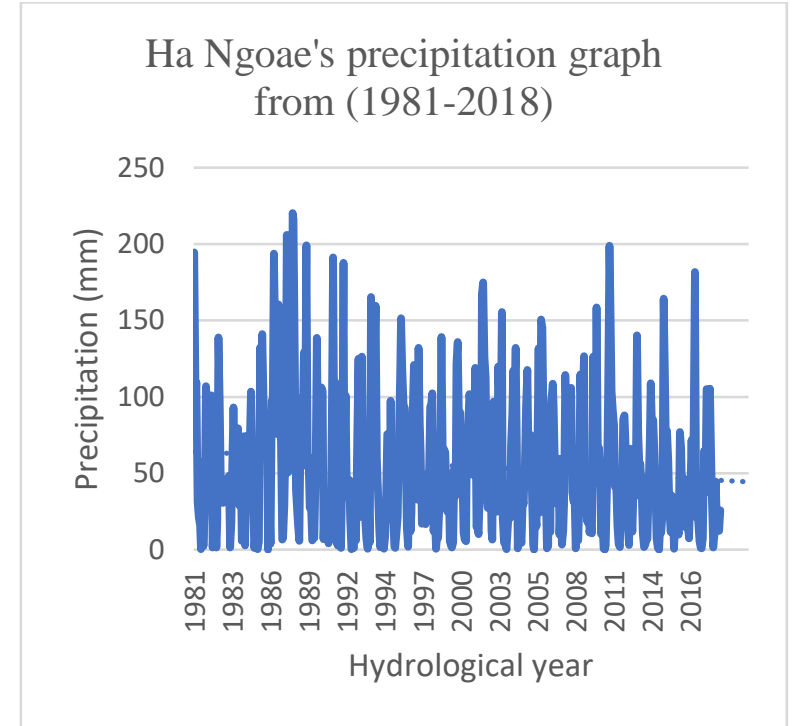

$\mathrm{C}$
Mount Olivet precipitation graph from (1981-2018)

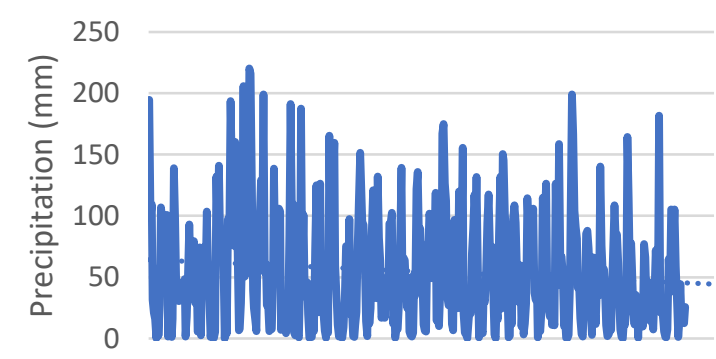

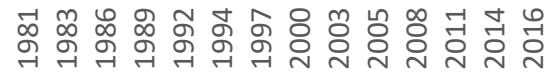

Hydrological year
Mount Tabor mission's precipitation graph from (19812018)

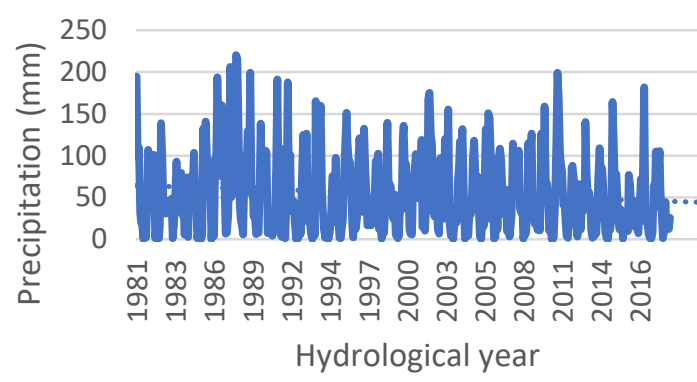

b

Ha Lekoatsa's precipitation graph from (1981-2018)

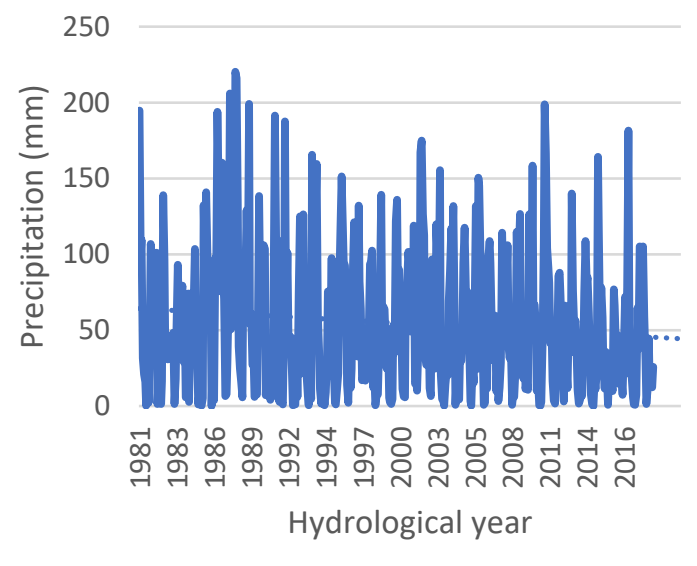

d

Ha Ramarothole's precipitation graph from (1981-2018)

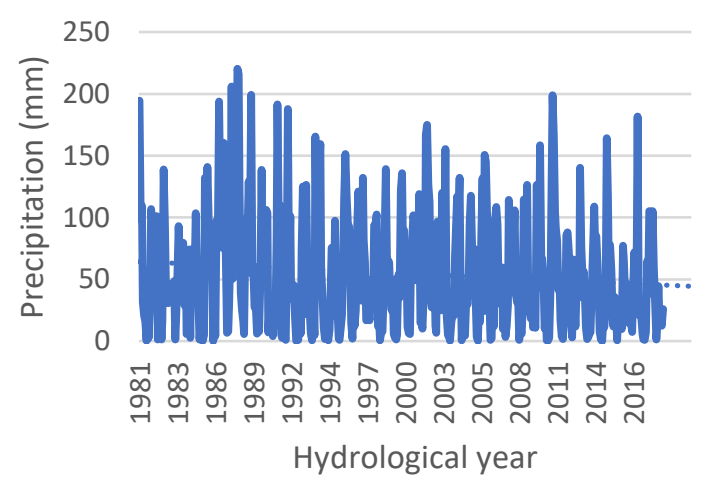




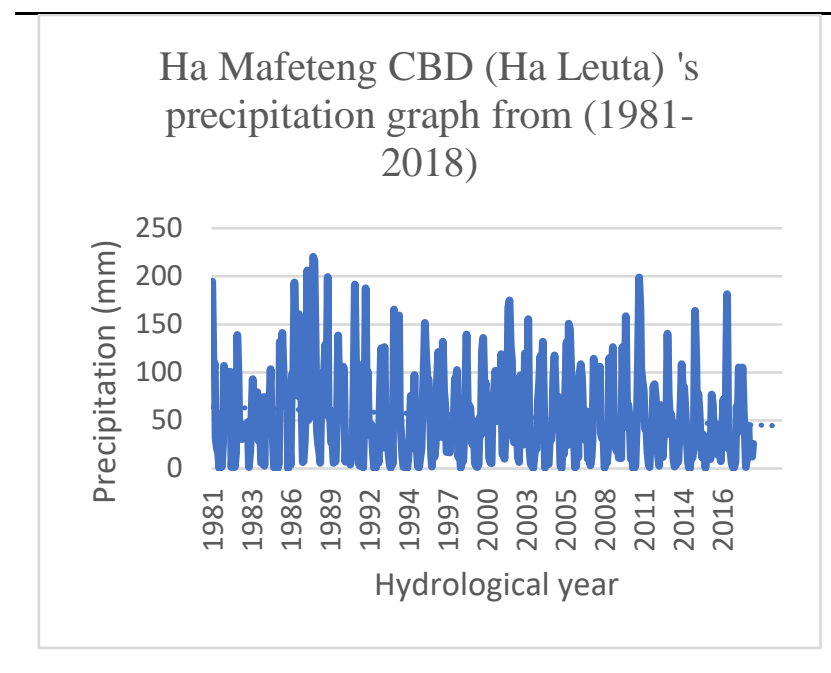

g

Figure 2. Thabana Morena stations total precipitation plot (1981-2018).

Figure 2 shows plots of precipitation over the selected stations. All rainfall datasets were subjected to drought quantification through the use of drought monitoring and prediction software (DMAP) on two temporal scales; SPI-3 and SPI-12. Figure 3 and 4 show the graphs of SPI-3 and SPI-12 at Ha Thakanyane and Ha Ramarothole. This dataset was further analysed for drought severity as shown in figure 5 and 6 . The two stations exhibited similar characteristics though Ha Ramarothole had the driest event in 2015/16. On SPI-3 that measures agricultural drought events, the two stations experienced constant drought episodes throughout the study record. The 2015/16 was a year when drought was declared a disaster in Lesotho. 

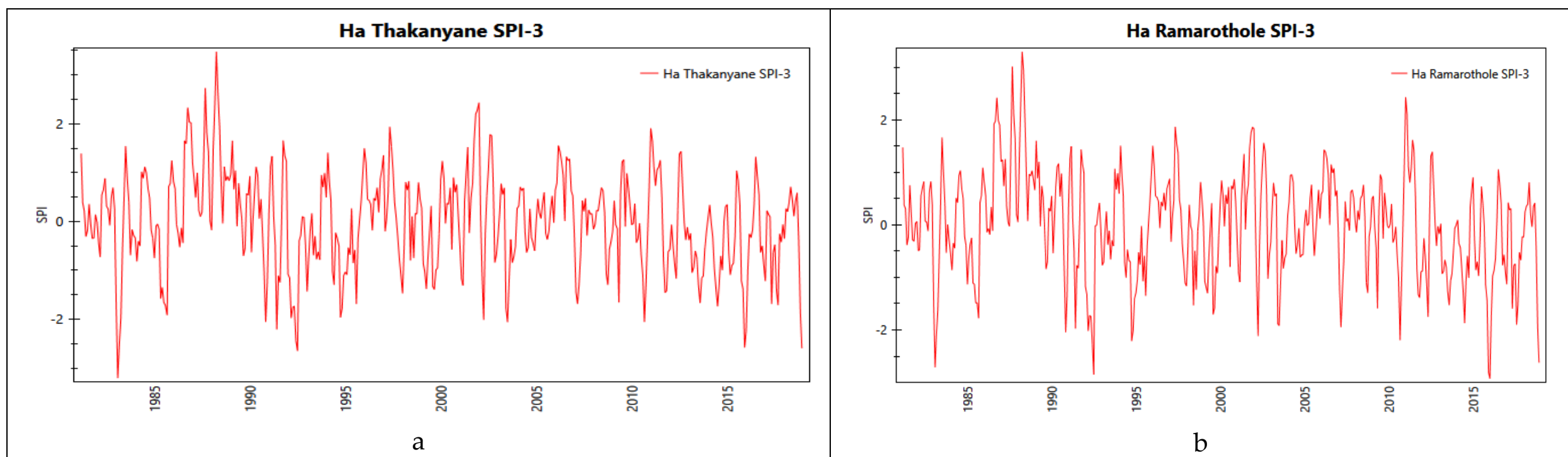

Figure 3: Thabana Morena stations SPI-3 plot (1981-2018)

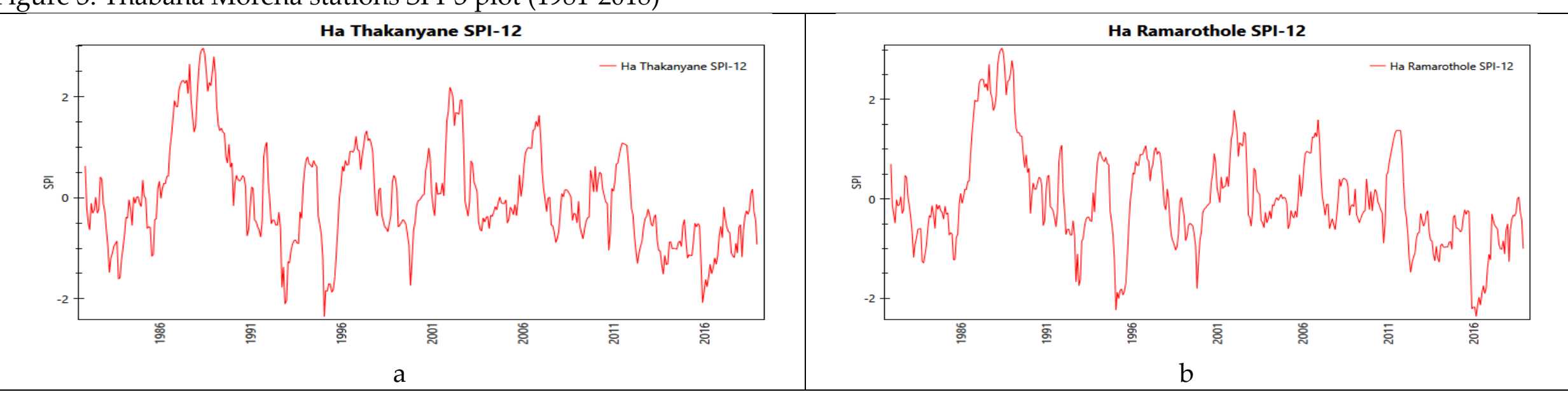

Figure 4. Thabana Morena stations SPI-12 plot (1981-2018). 

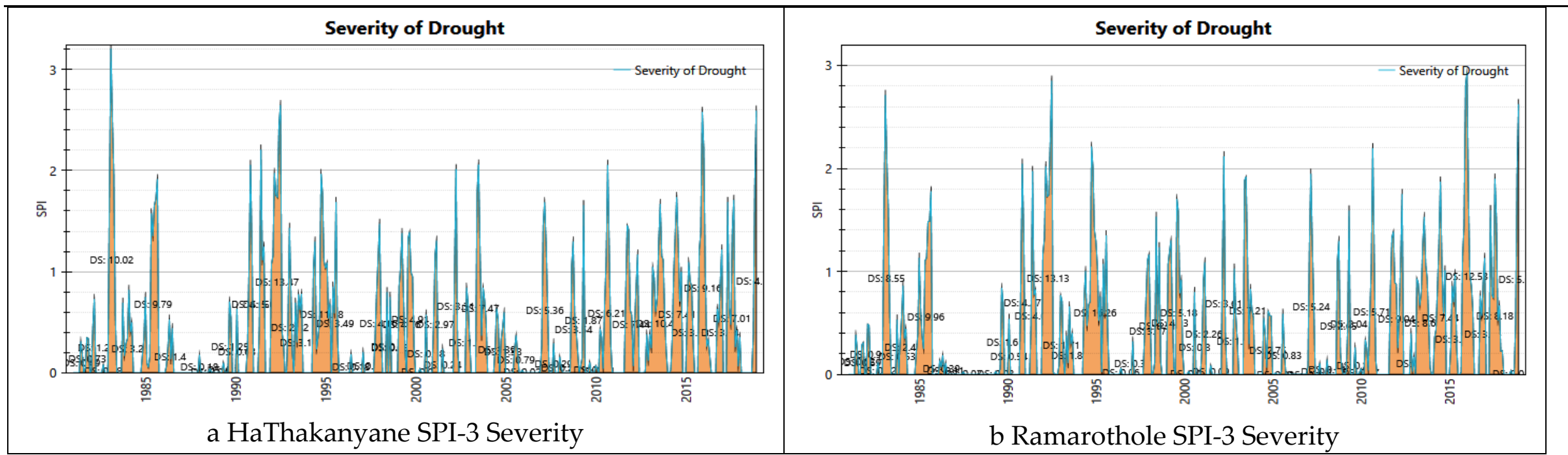

Figure 5. Thabana Morena stations SPI-3 drought severity (1981-2018).
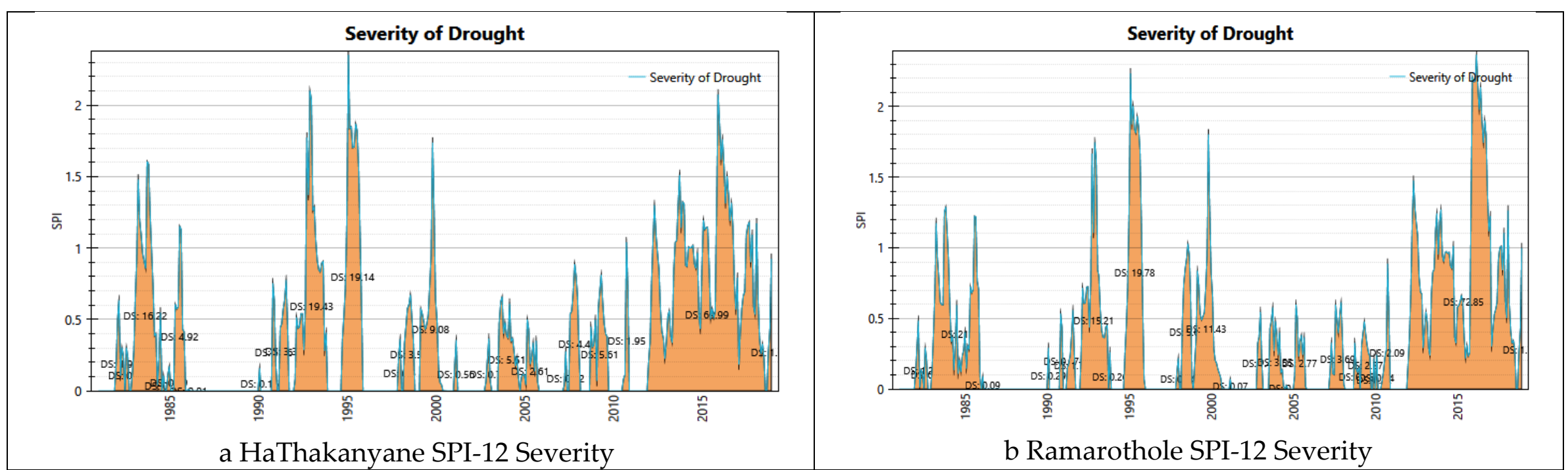
The 3rd International Electronic Conference on Atmospheric Sciences (ECAS 2020), 16-30 November 2020;

Sciforum Electronic Conference Series, Vol. 3, 2020

Figure 6. Thabana Morena stations SPI-12 drought severity (1981-2018). 


\section{sciforum}

Table 3. Descriptive statistics for Drought severity for Ha Thakanyane (SPI-3).

\begin{tabular}{cccccc}
\hline Variable & Observations & Minimum & Maximum & Mean & Std. deviation \\
\hline Duration of Drought & 54 & 28.000 & 457.000 & 124.537 & 97.745 \\
Severity of Drought & 54 & 0.024 & 13.474 & 3.324 & 3.466 \\
\hline
\end{tabular}

Table 4. Descriptive statistics for Drought severity for Ramarothole (SPI-3).

\begin{tabular}{cccccc}
\hline Variable & Observations & Minimum & Maximum & Mean & Std. deviation \\
\hline Duration of Drought & 55 & 28.000 & 518.000 & 121.836 & 100.821 \\
Severity of Drought & 55 & 0.000 & 16.260 & 3.246 & 3.823 \\
\hline
\end{tabular}

Table 5. Descriptive statistics for Drought severity for Ha Thakanyane (SPI-12).

\begin{tabular}{cccccc}
\hline Variable & Observations & Minimum & Maximum & Mean & Std. deviation \\
\hline Duration of Drought & 25 & 28.000 & 2404.000 & 305.400 & 475.356 \\
Severity of Drought & 25 & 0.013 & 69.990 & 6.968 & 14.325 \\
\hline
\end{tabular}

Table 6. Descriptive statistics for Drought severity for Ramarothole (SPI-12).

\begin{tabular}{cccccc}
\hline Variable & Observations & Minimum & Maximum & Mean & Std. deviation \\
\hline Duration of Drought & 26 & 28.000 & 2404.000 & 301.846 & 494.789 \\
Severity of Drought & 26 & 0.027 & 72.848 & 6.550 & 14.797 \\
\hline
\end{tabular}

Table 7. Mann Kendall's trend test on Severity.

\begin{tabular}{ccc}
\hline Station & SPI-3 & SPI-12 \\
\cline { 2 - 3 } & p-value & p-value \\
\hline Ha Thakanyane & 0.010 & 0.018 \\
\hline Ha Ramarothole & 0.170 & 0.932 \\
\hline
\end{tabular}

Tables 3 to 6 show descriptive statistics for Drought severity at SPI-3 and SPI-12 at the two selected stations. These two stations behaved almost in the same way. They are approximately $40 \mathrm{~km}$ apart. A Mann Kendall's trend test was applied to detect the presence of any monotonic trends present in the SPI-3 and 12 in the two candidate stations. Table 7 shows the results of this test. Ha Thakanyane showed statistically significant decreasing trends on both SPI-3 and 12 while Ha Ramarothole showed non-significant trends on both time scales. A decrease in SPI implies an increase in drought severity hence intensity and greater adverse effects on agriculture, water resources and Agri-projects and businesses. Ha Thakanyane's SPI-3 and 12 showed p-values of 0.010 and 0.018 which are both less than a significance level of 0.05 , while Ha Ramarothole had p-values of 0.170 and 0.932 that are greater than 0.05 significance level.

\section{Conclusion and Recommendations}

While some regions are likely to get wetter as the world warms up, other regions like Thabana Morena in Mafeteng, Lesotho are already on the dry side and are likely to get drier in the coming years. The current study used online collected precipitation dataset to characterise drought events on two temporal scales. Most selected stations alongside main Thabana Morena road showed similar behaviour in the rainfall that they receive and as such only two stations were used as proxy on further analysis. The area seems to be under continuous agricultural and hydrological stress over years, as shown by either decreasing nor increasing trend patterns in the SPI-3 and SPI-12 using a Mann Kendall's test. Of all drought events in the area, the 2015 drought seems to be the most severe since 1981. This drought started in 2012 on both stations and does not show any sign of decreasing in severity. At this stage it is appropriate to indicate that this study area is getting arid unless mitigation

The 3rd International Electronic Conference on Atmospheric Sciences (ECAS 2020), 16-30 November 2020;

Sciforum Electronic Conference Series, Vol. 3, 2020 
The 3rd International Electronic Conference on Atmospheric Sciences (ECAS 2020), 16-30 November 2020; Sciforum Electronic Conference Series, Vol. 3, 2020

and adaptation measures are taken. Governments, businesses, NGO's must identify area that mostly vulnerable to climate-induced extremities such as drought and implement adaptation or and mitigation measures in order to safe human lives. Actions such as using water more efficiently and developing more drought-resistant crops will help prepare for both future droughts and climate change.

\section{References}

1. Abarca del Rio, R., Gambis, D., Salstein, D., Nelson, P., \& Dai, A. (2003). Solar activity and earth rotation variability. Journal of Geodynamics, 36(3), 423-443. https://doi.org/10.1016/S0264-3707(03)00060-7

2. Abdulmalek, A., Asheikh \& Tarawneh, Q.Y. 2013. An analysis of Dry spell patterns Intensity and

3. duration in Saudi Arabia. Middle East Journal of Scientific Research. 13(3): 314-327.

4. Abraham, B., \& Yatawara, N. (1988). a Score Test for Detection of Time Series Outliers. Journal of Time Series Analysis, 9(2), 109-119. https://doi.org/10.1111/j.1467-9892.1988.tb00458.x

5. Andreadis, K. 2005. Trends in 20th century drought characteristics over the continental

6. UnitedStates.http://www.hydro.washington.edu/Lettenmaier/Presentations/2005/andreadis_UBCUW_20 05.pdf. Date of access: 20 Oct. 2019.

7. Ali, W., \& Ali, B. W. (2011). Drought and drought mangement.

8. Choi, J., An Prof., S. Il, Yeh, S. W., \& Yu, J. Y. (2013). ENSO-like and ENSO-induced tropical pacific decadal variability in CGCMs. Journal of Climate, 26(5), 1485-1501. https://doi.org/10.1175/JCLI-D-12-00118.1

9. Des Jardins, D. 2012. Incorporating drought risk from climate change into california water

10. planning.http://www.waterboards.ca.gov/waterrights/water_issues/programs/bay_delta/docs/comments 111312/deirdre_desjardins_2.pdf. Date of access: 01 Oct. 2019.

11. Do Amaral Cunha, A. P. M., Marchezini, V., Lindoso, D. P., Saito, S. M., \& Dos Santos Alvalá, R. C. (2019). The challenges of consolidation of a drought-related disaster risk warning system to Brazil. Sustentabilidade Em Debate, 10(1), 43-59. https://doi.org/10.18472/SustDeb.v10n1.2019.19380

12. Francisco, A. R. L. (2013). 済無 No Title No Title. Journal of Chemical Information and Modeling, 53(9), 16891699. https://doi.org/10.1017/CBO9781107415324.004

13. Gaas, A. O. (2018). Impact Assessment of Recurrent Droughts on Agricultural and Pastoral Communities in Somaliland. 6(4), 1411-1421.

14. Ghormar, B. K. T. B. R. (2014). Solar Interplanetary and Geomagnetic Activity in Solar Cycle 23. 2(07), 1-2.

15. Granzow-de la Cerda, I., Lloret, F., Ruiz, J. E., \& Vandermeer, J. H. (2012). Tree mortality following ENSOassociated fires and drought in lowland rain forests of Eastern Nicaragua. Forest Ecology and Management, 265, 248-257. https://doi.org/10.1016/j.foreco.2011.10.034

16. Hlalele, B.M. 2016. A probabilistic approach to drought frequency analysis in Mafube Local

17. Municipality, South Africa. Research Journal of Pharmaceutical, Biological and Chemical Sciences, 7(6): 3008-3015.

18. Hosseinzadeh Talaee, P., Kouchakzadeh, M., \& Shifteh Some'e, B. (2014). Homogeneity analysis of precipitation series in Iran. Theoretical and Applied Climatology, 118(1-2), 297-305. https://doi.org/10.1007/s00704-013-1074-y

19. Jordan, A. J. (2017). Vulnerability, Adaptation to and Coping with Drought: The Case of Commercial and Subsistence Rainfed Farming in the Eastern Cape. WRC Report Number: TT716/1/17. In Water Research Commission.

20. Keil, A., Zeller, M., Wida, A., Sanim, B., \& Birner, R. (2008). What determines farmers' resilience towards ENSO-related drought? An empirical assessment in Central Sulawesi, Indonesia. Climatic Change, 86(3-4), 291-307. https://doi.org/10.1007/s10584-007-9326-4

21. Khan, S. M., \& Gomes, J. (2019). Drought in Ethiopia: A Population Health Equity Approach to Build Resilience for the Agro-Pastoralist Community. Global Journal of Health Science, 11(2), 42. https://doi.org/10.5539/gihs.v11n2p42

22. Kliewer, J., \& Mertins, A. (1997). Design of paraunitary oversampled cosine-modulated filter banks. ICASSP, IEEE International Conference on Acoustics, Speech and Signal Processing - Proceedings, 3, 2073-2076. https://doi.org/10.1109/icassp.1997.599355

23. Lobato, I. N., \& Velasco, C. (2004). A simple test of normality for time series. Econometric Theory, 20(4), 671689. https://doi.org/10.1017/S0266466604204030 
The 3rd International Electronic Conference on Atmospheric Sciences (ECAS 2020), 16-30 November 2020;

Sciforum Electronic Conference Series, Vol. 3, 2020

24. Méthy, M., Damesin, C., \& Rambal, S. (1996). Drought and photosystem II activity in two Mediterranean oaks. Annales Des Sciences Forestières, 53(2-3), 255-262. https://doi.org/10.1051/forest:19960208

25. Minckley, R. L., Roulston, T. H., \& Williams, N. M. (2013). Resource assurance predicts specialist and generalist bee activity in drought. Proceedings of the Royal Society B: Biological Sciences, 280(1759). https://doi.org/10.1098/rspb.2012.2703

26. Minnis, C. M. (1958). Solar activity and the ionosphere. Nature, 181(4608), 543-544. https://doi.org/10.1038/181543a0

27. Nagamuthu, P., \& Rajendram, K. (2015). Occurrences of Flood Hazards in the Northern Region of Sri Lanka. J. S. Asian Stud, 03(03), 363-376. Retrieved from http://www.escijournals.net/JSAS

28. National Drought Mitigation Center (NDMC), 2012. What is drought?

29. http://drought.unl.edu/DroughtBasics/WhatisDrought.aspx. Date of access: 11 Nov. 2019.

30. Olivares Campos, B. O. (2016). Análisis temporal de la sequía meteorológica en localidades semiáridas de Venezuela. UGCiencia, 22(1), 11. https://doi.org/10.18634/ugcj.22v.1i.481

31. Orlando Olivares, B., \& Zingaretti, M. L. (2018). Análisis de la sequía meteorológica en cuatro localidades agrícolas de Venezuela mediante la combinación de métodos multivariados. UNED Research Journal, 10(1), 181-192. https://doi.org/10.22458/urj.v10i1.2026

32. Praveen, D., Ramachandran, A., Jaganathan, R., Krishnaveni, E., \& Palanivelu, K. (2016). Projecting droughts in the purview of climate change under RCP 4.5 for the coastal districts of South India. Indian Journal of Science and Technology, 9(6). https://doi.org/10.87677/ijst/2016/v9i6/87677

33. Prokurat, S. (2015). Drought and water shortages in Asia as a threat and economic problem. Journal of Modern Science, 26(3), 235-250.

34. Rahmat, S. N., Jayasuriya, N., \& Bhuiyan, M. (2012). Trend analysis of drought using Standardised Precipitation Index (SPI) in Victoria, Australia. Proceedings of the 34th Hydrology and Water Resources Symposium, HWRS 2012, (1996), 441-448.

35. Román-Cuesta, R. M. (2007). Environmental and human factors influencing fire trends in ENSO and nonENSO years in tropical Mexico (Ecological Application (2003) 13, (1177-1192)). Ecological Applications, 17(5), 1555. https://doi.org/10.1890/1051-0761(2007)17[1555:E]2.0.CO;2

36. Potop, V., Boroneant, C., Možný, M., Štěpánek, P. \& Skalák, P. 2013. Observed spatiotemporal

37. characteristics of drought on various time scales over the Czech Republic. Theoretical and Applied Climatology. 112(4): 1-21.

38. Ryu, J. H., Svoboda, M. D., Lenters, J. D., Tadesse, T., \& Knutson, C. L. (2010). Potential extents for ENSOdriven hydrologic drought forecasts in the United States. Climatic Change, 101(3), 575-597. https://doi.org/10.1007/s10584-009-9705-0

39. Siingh, D., Singh, R. P., Singh, A. K., Kulkarni, M. N., Gautam, A. S., \& Singh, A. K. (2011). Solar Activity, Lightning and Climate. Surveys in Geophysics, 32(6), 659-703. https://doi.org/10.1007/s10712-011-9127-1

40. Sobrino, J.A. \& Julien, Y., 2011. Global trends in NDVI-derived parameters obtained from GIMMS

41. data. International Journal of Remote Sensing, 32(15): 4267- 4279.

42. Solheim, J.-E., Stordahl, K., \& Humlum, O. (2011). Solar Activity and Svalbard Temperatures. Advances in Meteorology, 2011, 1-8. https://doi.org/10.1155/2011/543146

43. Tadić, T., Dadić, T. \& Bosak, M. 2015. Comparison of different drought assessment methods in

44. continental Croatia. DOI: 10.14256/JCE.1088.2014. Date of access: 20 Sep. 2019.

45. Tan, B., \& Ylmaz, K. (2002). Markov chain test for time dependence and homogeneity: An analytical and empirical evaluation. European Journal of Operational Research, 137(3), 524-543. https://doi.org/10.1016/S0377-2217(01)00081-9

46. Technology, B., \& Bay, H. K. (2001). Department of Electrical and Computer Engineering, University of Patras, 26500 Rion, Patras Department of Electrical and Computer Engineering, University of Patras 1 Computer Science Department, University of Ioannina. (October).

47. Tefera, A. S., Ayoade, J. O., \& Bello, N. J. (2019). Comparative analyses of SPI and SPEI as drought assessment tools in Tigray Region, Northern Ethiopia. SN Applied Sciences, 1(10). https://doi.org/10.1007/s42452-019-1326-2

48. Van Niekerk, D. 2011. Introduction to disaster risk reduction. Potchefstroom: The African Centre

49. for Disaster Studies NWU Potchefstroom. 
The 3rd International Electronic Conference on Atmospheric Sciences (ECAS 2020), 16-30 November 2020;

Sciforum Electronic Conference Series, Vol. 3, 2020

50. Verma, M. K., Verma, M. K., Yadu, L. K., \& Murmu, M. (2016). Drought analysis in the seonath river basin using reconnaissance drought index and standardised precipitation index. International Journal of Civil Engineering and Technology, 7(6), 714-719.

51. Xiao, J., \& Zhuang, Q. (2007). Drought effects on large fire activity in Canadian and Alaskan forests. Environmental Research Letters, 2(4), 1-6. https://doi.org/10.1088/1748-9326/2/4/044003

52. Yuliang, Z., Li, L., Ping, Z., Juliang, J., Jianqiang, L. \& Chengguo, W. 2014. Identification of drought

53. and frequency analysis of drought characteristics based on palmer drought severity index model. The Chinese Society of Agricultural Engineering. 30(23):174-184.

54. Yusof, F., Hui-Mean, F., Suhaila, J., Yusop, Z., \& Ching-Yee, K. (2014). Rainfall characterisation by application of standardised precipitation index (SPI) in Peninsular Malaysia. Theoretical and Applied Climatology, 115(3-4), 503-516. https://doi.org/10.1007/s00704-013-0918-9

(C) 2020 by the authors. Submitted for possible open access publication under the terms and conditions of the Creative Commons Attribution (CC BY) license (http://creativecommons.org/licenses/by/4.0/). 